Custódio, Idália; Maria Aliete Farinho Galhoz; Isabel CARdigos: Património Oral do Concelho de Loulé. 5 vols. Loulé: Câmara Municipal de Loulé, 2004-2013, vol. I 503 p.; vol. II 3I8 pp + CD.; vol. III 453 pp + CD.; vol. IV 429 pp + CD.; vol. $\mathrm{V} 405 \mathrm{p}$.

\title{
Património Oral do Concelho de Loulé
}

Sandra Bото

Universidade do Algarve, Faro

Quando, em I870, Estácio da Veiga publicou o seu Romanceiro do Algarve (que se destacou por ser a primeira colecção da região do Algarve e uma das primeiras em Portugal dedicada à literatura tradicional), muito longe se estaria de prever que uma obra tão completa, de cariz concelhio, viesse algum dia a lume. A obra a que me refiro é, naturalmente, Património Oral do Concelho de Loulé.

Uma primeira advertência serve para fornecer ao leitor as coordenadas deste trabalho. Loulé é uma cidade da região do Algarve, ao sul de Portugal, situada a norte da capital de distrito, Faro. O concelho de Loulé pauta-se por apresentar uma rica heterogeneidade territorial e sociocultural, com aldeias que preservam ainda hoje vivências e práticas ancestrais como é exemplo a literatura de tradição oral, objeto da obra em apreço.

Do ponto de vista científico, a equipa que assina Património Oral do Concelho de Loulé, Idália Farinho Custódio, Isabel Cardigos e Maria Aliete Farinho Galhoz oferece, desde logo, a garantia de que a obra corresponde aos mais elevados critérios de recolha e fixação. Ou não estivéssemos perante três autoras de reconhecido mérito nos estudos e na edição dos textos literários de tradição oral. Idália Farinho Custódio, professora natural do concelho de Loulé, conta com uma larga experiência no levantamento e edição do património oral do seu concelho, como já auspiciava a sua prestação nos dois magníficos volumes da Memória Tradicional de Vale Judeu, de 1996 e I997. Maria Aliete Farinho Galhoz dispensará grandes apresentações, pois o seu magistério em Portugal na área da literatura popular e da crítica textual, enquanto investigadora do Centro de Tradições Populares Portuguesas e discípula do Professor Lindley Cintra, é inquestionável e prolixo, onde caberá destacar, para a área que nos interessa, o seu monumental Romanceiro Popular Português, de I987-88. Já a Professora Isabel Cardigos, que me incentivou a dar os primeiros passos na literatura tradicional, é simplesmente uma das estudiosas do conto mais respeitadas a nível internacional, responsável pelo Arquivo do Conto Tradicional Português, pelo Arquivo Português de Lendas, autora do Catalogue of Portuguese Folktales (2006) ${ }^{\mathrm{I}}$ e co-fundadora do Centro de Estudos Ataíde Oliveira, na Universidade do Algarve.

Do ponto de vista organizativo, distribuída em cinco volumes, três dos quais acompanhados de CD, a publicação desta obra iniciou-se em 2004, com o volume dedicado aos «Contos», da responsabilidade editorial de Isabel Cardigos. Em 2006 sairia o segundo volume, dedicado aos «Romances», da responsabilidade de Maria Aliete Galhoz; o terceiro volume, o das «Orações», é de 2008, tendo a

I. CARDigos, Isabel (2006): Catalogue of Portuguese Folktales. With the collaboration of Paulo Correia and J. J. Dias Marques. Folklore Fellows' Communications 29r. Helsinki: Soumalainen Tiedeakatemia. 
cargo da edição Idália Farinho Custódio e Maria Aliete Galhoz; o «Cancioneiro», o quarto volume, data de 20 I e a edição é novamente de Idália Farinho Custódio e Maria Aliete Galhoz; por fim, seria publicado em 2013 um último volume, uma «Vária. Adivinhas. Rezas e Benzeduras. Lendas. Adenda», cuja fixação textual é também assinada pelas duas últimas investigadoras mas com um texto teórico dedicado às lendas da autoria de Isabel Cardigos.

Como se adivinha, trata-se de uma obra não só de grande fôlego editorial mas também colector, uma vez que os espécimes editados provêm do enorme esforço e empenho que as suas responsáveis puseram ao longo de várias décadas de trabalho, particularmente de Idália Farinho Custódio.

Contabilizámos, para a totalidade da publicação, mais de I70o versões de espécimes. Será necessário referir que o plano editorial inicial desta colecção não previa, inicialmente, a publicação dos 5 volumes, mas apenas dos 3 primeiros, ou seja, o volume dos «Contos», dos «Romances» e o das «Orações». As recolhas foram, na verdade, orientadas para estes três géneros, segundo confessa Idália Farinho Custódio na "Nota sobre a realização da pesquisa» incluída nos volumes II, III, IV e V e como deixa bem transparecer a quantidade de versões de contos, romances e orações oferecidos nesta colecção. No entanto, pese embora direcionada para estes três géneros maiores da literatura de tradição oral, o trabalho de recolha plasmado nesta obra vem revelar também um extraordinário acervo de cantigas, quadras e rimas infantis, por um lado, e de adivinhas, rezas e benzeduras e ainda de lendas, por outro, que afortunadamente pôde ser dado a conhecer graças ao prolongamento da obra em dois volumes adicionais, os dois últimos. Saudamos, naturalmente, a sensibilidade daqueles que aceitaram proceder à ampliação deste projecto editorial, através da qual se logrou divulgar uma não menos importante parcela da memória tradicional louletana.

Património Oral do Concelho de Loulé ostenta, ao longo dos 5 volumes, uma lógica e uma coerência conseguida pelos seus paratextos, que se repetem, com pequenas adaptações, em todos os livros. Já cada «Introdução» e cada redacção dos «Critérios editoriais» são da responsabilidade de quem coordena cada volume ou a edição de cada género, sendo a primeira um texto deveras importante pelo muito útil enquadramento que oferece sobre cada género literário e o segundo, quanto a nós, um paratexto igualmente importante mas a requerer alguns reparos que especificaremos a seu tempo. Destacamos ainda a coerência conferida à obra pela inserção de uma secção final de «Notas e comentários» em todos os volumes, sem dúvida local de grande erudição e de consulta obrigatória para aqueles que não dispensam aprofundar informação sobre os textos com remissão para o seu contexto internacional, sempre que possível, não já referentes de forma sumária a cada género, mas incidindo sobre cada tipologia ou tema em particular. A inclusão de listas bibliográficas em todos os volumes é digna de ser ressaltada e elogiada, por se afirmarem estas como instrumentos de apoio incontornável aos investigadores. Resta, para já, na fase preliminar desta análise, destacar a extrema utilidade dos diferentes tipos de índices propostos para cada volume, com referência para os sistemas de classificação dos géneros (quando os há). Não obstante, sentimos a falta, no volume $\mathrm{V}$, de índices reunidos relativos a toda a colecção, sem dúvida proveitosos, e que teriam conferido unidade perante a dispersão da informação e dos textos pelos diferentes volumes. 
Em jeito de breve comentário geral e transversal a toda a colecção, deveremos enfatizar ainda a clareza e a concisão com que os critérios de fixação adoptados são expostos. A sua homogeneidade e o respeito grosso modo por critérios fundamentais de fixação ao longo dos 5 volumes inscreve-se também como uma das suas maiores virtudes, bem como o facto de se terem abandonado, na fixação, as sempre infrutíferas tentativas de mimetização ortográfica dialectal (neste caso algarvia). Louvamos o facto de as responsáveis por este Património Oral do Concelho de Loulé terem rejeitado adoptar essa prática lamentavelmente comum em edições de literatura de tradição oral que conduz à penetração em campos que não lhe dizem necessariamente respeito como o da fonética, confusão esta gerada devido ao facto de o objecto de estudo da literatura tradicional coincidir com o da fonética, com o da etnografia ou com o da antropologia no tratamento de enunciados veiculados através da oralidade.

Entremos agora na análise de cada volume. Para o primeiro, o dos «Contos», gostaríamos de destacar o rigor com que Isabel Cardigos se preocupou em organizar a disposição das I59 versões fixadas de acordo com a classificação por tipos contísticos referentes ao índice de autoridade mais reconhecido internacionalmente, o Aarne e Thompson (AaTh), ${ }^{2}$ só recorrendo a outros sistemas de classificação, como o seu próprio, quando AaTh não apresenta solução para a versão em causa. No entanto, sugerimos, para uma reedição da obra, a elaboração de um índice de correspondência entre os vários sistemas de classificação do conto tradicional, uma vez que, nalguns casos, como o da versão 23, se classifica o conto através do código conferido pelo índice Aarne-Thompson (AaTh 403A), mas atribui-se-lhe um título convencional proposto por outro índice, o Ca-Ch. Este caso apresenta-se devidamente fundamentado, é certo, mas não deixa por isso de lembrar a necessidade de um índice de correspondência entre sistemas de classificação.

Consiste, esta, numa colecção contística com diferentes proveniências, fruto, pela maior parte, de recolhas éditas e inéditas dirigidas por Idália Farinho Custódio. Algumas versões da informante Filipa Faísca já haviam sido anteriormente editadas na obra Povo, Povo, eu te Pertenço. Também os contos dados à estampa em Memória Tradicional de Vale Judeu foram aqui reeditados. Na apresentação de cada versão, dá-se preferência ao título atribuído pelo informante ao conto, sendo apresentado apenas o título genérico (entre parêntesis rectos) quando o informante não apresenta o seu título, o que origina uma dispersão de títulos para o mesmo tipo, como sucede, por exemplo, com o conhecido conto-tipo AaTh 300, «O matador do dragão» (p. 47-57). Embora o número de identificação do conto na obra seja o mesmo, com uma alínea diferente para cada versão (I2a, I2b, I2c), factor que permite reconhecer a priori que se trata do mesmo modelo contístico, entendemos que se introduz através desta prática uma dificuldade acessória e desnecessária no manejamento da obra.

O sistema de notas e comentários incluídos por Isabel Cardigos a partir da página 4I7, que transparece o profundo conhecimento que a investigadora tem do conto tradicional, reveste-se de uma importância vital para o acompanhamento da leitura das versões, elucidando muitos aspectos relacionados com os tipos e com as versões em causa, chamando (e muito bem) a atenção para outras versões

2. AARne, Antti; Stith Thompson (I96I): The Types of the Folktale. A Classification and Bibliography. Folklore Fellows' Communications I84. Helsinki: Suomalainen Tiedeakatemia. 
algarvias do mesmo tipo já publicadas. A alusão bibliográfica a versões de outras regiões de Portugal só é efectivada sempre e quando não se conheçam outras versões do mesmo conto em território algarvio. Discordamos desta opção, na medida em cremos que a existência de versões algarvias não dispensa em nenhuma ocasião o recurso a versões de outras áreas geográficas para o estudo do conto e da literatura tradicional em geral, pelo que a oferta desta indicação entendida como segundo recurso deveria ser, pelo contrário, obrigatória, e não secundária. Por outro lado, gostaria ainda de chamar a atenção para o facto de, em nota, o critério de identificação dos textos a que se referem os comentários dever ter tido em consideração o primeiro critério de identificação das versões no corpo textual, ou seja, o número de identificação e não o título (atribuído pelo informante ou genérico). Trata-se apenas de uma crítica de ordem formal, é certo, mas simplificaria a consulta da obra se o primeiro elemento de identificação entre texto e respectiva nota coincidisse.

Pese embora estes pequenos reparos mais ou menos formais, destacaria neste primeiro volume as excelentes resenhas históricas patentes nalguns comentários como o da versão 24 (p. 43I-432), que surpreendem pela erudição de Isabel Cardigos. Neste caso exemplar, é-nos oferecido percurso da presença do conto «As três cidras do amor» ao longo da história da literatura portuguesa . Outros casos poderíamos invocar, mas deixamos ao leitor a interessante descoberta destas notas e comentários ao volume «Contos».

Passando agora para o volume II, o dos «Romances», que alberga um total de I9I versões de romances de 42 temas e 33 versões de cantigas narrativas, chama-nos a atenção a excelente qualidade da recolha conseguida. Sabemos bem como a perda de funcionalidade do romanceiro profano (não tanto do devoto e do religioso) conduz fatalmente a que este género alcance actualmente uma persistência extremamente reduzida na memória tradicional. Os números são, pois, expressivos: este volume congrega $5 \mathrm{I}$ versões de romances tradicionais e vulgares profanos, contra I40 de romances devotos e religiosos. Noutro ângulo de análise, observamos o desaparecimento completo do romanceiro histórico, a quase inexistência do romanceiro carolíngio (subsistem apenas 4 versões do tema «Conde Claros em hábito de frade» e uma predominância de romances de temática novelesca). No entanto, se confrontarmos esta estatística apressada com os resultados da última grande recolha regional, publicada em I988 e realizada nos inícios dessa década, da responsabilidade de Vanda Anastácio, verificamos que o passar do tempo não ditou a perda significativa de temas recolhidos, uma vez que já durante os anos 80 a preponderância de um romanceiro devoto e religioso era uma realidade, o romanceiro histórico já era inexistente no Algarve e o carolíngio já se resumia ao mesmo tema aqui fixado.

Nesta edição, optou-se por seguir o sistema classificativo de Pere Ferré e Cristina Carinhas, patente na Bibliografia do Romanceiro Português da Tradição Oral Moderna (I828-2OOO), que tem por base o internacional Índice general del romanceiro (IGR). Como alternativa, para os casos de romances não contemplados neste sistema ou para o romanceiro religioso, que lamentavelmente ainda não tem uma colecção ou catálogo publicado para a tradição portuguesa, segue-se o sistema classificativo de Manuel da Costa Fontes patente n' O Romanceiro Português e Brasileiro: Índice Temático e Bibliográfico. Parece-nos ser um critério correcto. 
Não podemos estar de acordo, contudo, com a inclusão, neste volume, de um apêndice dedicado às cantigas narrativas. A própria Maria Aliete Galhoz reconhece que se trata de uma «infracção de limites» (p. I7). Na verdade, esta crítica não assenta em nenhum tipo de preconceito contra o género poético cantiga narrativa mas no facto de, apesar de este género narrar uma história em verso e desse prisma coincidir com o romance, não comungar das características formais deste, nomeadamente no que respeita a uma estrutura estrófica em jeito de quadra. Mas mais determinante do que o aspecto formal (os romances de origem baladística ostentam também uma estrutura estrófica primitiva, é certo) é o aspecto poético. O estilo de uma cantiga narrativa não partilha do tratamento poético e retórico típicos do romanceiro medieval, munindo-se de um código retórico e poético particulares, embora reconheçamos algumas temáticas comuns entre cantiga narrativa e romanceiro. Na verdade, trata-se de um género que assume uma origem completamente distinta, não devendo inscrever-se, como alguns estudiosos pretendem, no filão da velha poesia narrativa medieval, de origem épico-baladística. Por este motivo não compreendemos o motivo pelo qual este acervo de 33 versões não ficou destinado à «Vária», como ficaram as lendas cujas relações com o conto à partida até podem parecer difusas para não especialistas, nalguns casos, ou as benzeduras, expurgadas do volume das «Orações», por motivos semelhantes.

Do ponto de vista formal, reitera-se a crítica apontada anteriormente no que diz respeito à manutenção dos títulos dados pelos informantes para cada versão. Também a manutenção de refrões bem como de didascálias e «contribuições em prosa» no corpo do texto faz parte de um tipo de fixação que pretende uma mimetização do momento performativo, da oralidade, dando conta de elementos que são afins a uma reprodução que capta as falhas de memória ou outros elementos meramente circunstanciais; por outro lado, a manutenção do refrão vincula ao texto o seu carácter musical, quando a transcrição musical deveria consistir num documento autónomo, na medida em que este é determinado por regras e técnicas particulares que não interferem (ou não devem interferir) no documento literário e que as próprias autoras reconhecem.

Do ponto de vista teórico propriamente dito, enaltecemos a forma como as classificações são atribuídas às versões, ao nível fabulístico e pelo tema preponderante, quando sabemos que o romance é um género tão propenso à contaminação com a confluência, numa versão, de mais do que um tema, muitas vezes. Esta tarefa só aparentemente é simples, sobretudo quando nos referimos a textos religiosos, em que uma versão pode constituir um verdadeiro «mosaico». As editoras deste volume mostraram um domínio insuperável relativamente a este assunto.

Um último comentário vai para o interessante artigo de Isabel Cardigos introduzido no final do volume, com o título «Como um romance se torna num conto». Neste texto invoca-se o romance «Donzela guerreira» e a relação de proximidade com o conto AaTh $884 \mathrm{~B}^{*}$, «A rapariga vestida de homem engana o rei», oriundo de uma colecção russa e mencionado no catálogo de Aarne e Thompson, de I96I, onde «se reconhece (...) o enredo de 'A donzela guerreira'». Contudo, este subtipo foi excluído da classificação numa mais recente reedição do referido catálogo por Uther, devido, certamente, a dúvidas sobre a fiabilidade da sua atribuição ao género conto. Muito provavelmente, este subtipo $884 \mathrm{~B}^{*}$ consistiria numa versão da balada prosificada, como se torna manifesto a partir de três casos comentados por Isabel Cardigos, três versões prosificadas do romance existentes 
no Arquivo Português de do Contos Tradicionais. Estes textos apresentam uma característica comum, que é a libertação daquilo que Isabel Cardigos denomina graciosamente o «freio do verso» (p. 243-244), com algumas significativas alterações ao nível da intriga, onde o maravilhoso chega a intervir. Mas a grande questão que importa colocar, creio, será: por que motivo os informantes abandonam a forma versificada para dar lugar a um conto? Sem dúvida porque este romance apresenta características muito particulares, afins ao conto tradicional, como as sequências de provas e o reconhecimento. Uma das versões prosificadas utilizadas como exemplo pela investigadora foi recolhida por mim no ano 20oo. Só pouco mais tarde descobri que se tratava de uma versão de um romance e obtive, entretanto, uma recitação do romance na sua forma versificada junto da informante. Como é de esperar, actualmente rejeito completamente esse texto recolhido, que não passa de um erro de recolha a uma informante que ostenta uma clara predilecção por géneros em prosa, tendo subestimado desde sempre a capacidade do seu auditório para processar a fábula de um romance com as todas ambiguidades poéticas características do género. Tal como Uther rejeitou do catálogo aquela versão russa do conto, duvidosa, provavelmente por ter descoberto a sua filiação na balada, à luz da minha (in)experiência recolectora em 2000, penso que devemos cautela na abordagem destes casos de migração entre géneros. Eles assentam em motivos bem mais prosaicos e circunstanciais do que num movimento consciente e soberano da tradição oral.

A partir do terceiro volume, as editoras de Património Oral do Concelho de Loulé enfrentam um problema acrescido que as obriga à tomada de opções editoriais mais arriscadas. Se, para o conto e para o romanceiro, contamos com índices de autoridade internacionais válidos que as responsáveis pela edição seguiram com toda a segurança, tal não se verifica para os géneros oração, cancioneiro ou adivinhas. O caso das Lendas é distinto, pois o indispensável Arquivo Português de Lendas <www.lendarium.org> da responsabilidade de Isabel Cardigos e Paulo Correia desenvolveu uma classificação empírica que se instituiu já como critério de autoridade em contexto académico.

Relativamente às «Orações» dadas a lume no volume III, é a própria editora quem reconhece que se trata do «acervo de maiores dificuldades de apresentação» (p. I6). Dando a conhecer o impressionante número de 477 versões de orações, esclarece a editora que as orações tradicionais aqui incluídas são as da «prática orante comum, da privacidade, a grande maioria, ou de expressão colectiva próxima» (p. I7), organizadas de acordo com um sistema temático extremamente coerente, da sua lavra. Igualmente irrepreensível é o estudo introdutório deste volume assinado por Maria Aliete Galhoz e Idália Farinho Custódio, pelo debate esclarecedor e rigoroso em torno do problema da definição do género e das inúmeras especificidades atinentes ao grande grupo classificativo da oração. Não discutiremos a opção de expurgar neste volume as «Rezas e benzeduras» por se associarem a práticas curativas e, portanto, assumirem uma natureza bastante distinta. A justificação é coerente. Mas questionamos, então, o facto de os «Benditos», cânticos religiosos associados numa primeira instância a práticas institucionais da Igreja e sem função de oração, caberem neste volume. Talvez futuramente possam ser afinados critérios relativamente a este assunto.

Igualmente de elogiar é a tomada de critérios de fixação particularmente orientados para o oracioneiro, tendo em conta as especificidades dos textos. 
Compreendemos a necessidade de seleccionar os textos fixados, nos casos em que estamos perante lições vulgata, devido ao elevado número de versões recolhidas, mas notamos que a indicação dessa escolha, quando a houve, deveria ter sido assinalada no capítulo das «Notas e comentários». Relativamente à apresentação, no final de alguns textos, de notas das informantes sobre a crença ou sobre os contextos funcionais de algumas orações, cremos tratar-se de elementos de grande interesse no âmbito dos estudos etnográficos (não tanto no contexto dos estudos literários).

Uma chamada de atenção especial vai, neste volume, para o capítulo das «Notas e Comentários» que, se nos volumes anteriores, já se destacava pela erudição, neste volume é de consulta absolutamente incontornável. Não se trata já de um sistema de notas caso a caso, devido ao elevado número de textos incluído no volume, mas a gama de assuntos elucidados em sede de nota e comentário, relativos à origem, percurso editorial, geografia, funcionalidade dos temas ou relações com outros géneros tradicionais é bem revelador da qualidade do trabalho de Galhoz-Custódio sobre este género, que continua a formular tantas questões. De destacar é também o excelente tratamento das relações intrincadas entre as orações (sobretudo das orações da paixão, mas não só) com o romanceiro religioso, assunto que sabemos levantar problemas extremamente complexos e que as editoras tratam com grande conhecimento de causa.

Já o IV volume da obra, o do «Cancioneiro», se encontra claramente dividido em duas secções textuais: uma primeira dedicada às cantigas e uma segunda às quadras. Dotado de enorme funcionalidade tradicional, contabilizamos para o cancioneiro um total de 80 espécimes de quadras soltas e 277 de cantigas fixados nesta obra.

As cantigas surgem organizadas de acordo com critérios gerais de funcionalidade e de contexto performativo das mesmas, sem referência a sistemas de classificação, pelo que inferimos que a disposição dos textos no volume obedece a critérios empíricos definidos pelas editoras, embora careçamos dessa informação. Do ponto de vista da definição de critérios de edição, detectamos uma clara alteração entre a primeira e a segunda parte da obra, devido às particularidades do repertório em causa. Verifica-se, na verdade, neste volume como em nenhum anterior, uma certa tensão, diria, entre a reprodução mimética dos repertórios dos informantes através da manutenção, em termos editoriais, da ordem em que os textos foram cantados e entre a disposição temática dos mesmos. Dever-se-á esta característica à ausência de critérios temáticos classificativos previamente definidos, pensamos. Não criticamos a opção casuística de abandono da fixação temática nos Cantos ao Menino e nos Cantos de Janeiras e Reis (a partir da p. I9I), com o objectivo de reproduzir o repertório dos informantes, abrindo-se uma excepção editorial nesta primeira parte (as restantes cantigas encontram-se tematicamente organizadas e não tendem a reflectir o contexto de recitação). O que já se afigura mais complexo é a opção de editar conjuntos de quadras, com o objectivo de «não se desmembrarem os repertórios pessoais prestados» (p. 377). Intriga-nos esta alteração de critérios, na medida em que as mesmas editoras assumem que «os dadores lembravam [as quadras] de maneira avulsa, recitando-as» (p. 377). Daqui se pode concluir que, tratando-se de uma recitação sem um fio condutor lógico, a insistência na manutenção da ordem de recitação não conduz à reprodução de 
um repertório com significado definido (ao contrário do que se admite para os Cantos ao Menino ou Canto das Janeiras).

Por fim, um último comentário a este volume prende-se com a ausência de um índice de primeiros versos relativo às cantigas, enquanto as quadras estão contempladas num índice desta tipologia. Talvez futuramente se possa remediar esta lacuna.

Passando finalmente em revisão o V e último volume, a «Vária», destacamos a publicação de distintos corpora, sendo o mais significativo, em termos quantitativos, o das adivinhas, com 424 versões, seguido do das «Rezas e benzeduras», com 56 espécimes. Figuram também 24 espécimes de «Lendas» tradicionais, às quais se segue uma Adenda constituída por algumas versões de contos, romances, cantigas narrativas e orações recolhidas após a publicação dos volumes dedicados a estes géneros.

A colecção de adivinhas, que constitui um núcleo textual de extremo interesse, é precedida de uma «Introdução» onde se problematiza a natureza da adivinha enquanto género e se comenta uma classificação temática proposta por Carlos Nogueira. Contudo, esta classificação acaba por não servir de referência para a organização das adivinhas nesta obra. Aqui prevalece novamente o critério de manutenção do repertório do informante, à semelhança do que registámos para as quadras. Ou seja, cada espécime coincide com uma tirada de adivinhas e não com cada versão de adivinha. Discordamos desta opção pelos motivos apontados antes. Elogiamos, sim, a inclusão de uma tábua de soluções para as adivinhas, que contribui para a compreensão do verdadeiro alcance do jogo retórico veiculado por cada composição.

O corpus de «Rezas e Benzeduras» deste volume V abarca versões relacionadas com invocações curativas, sendo precedido por uma «Introdução» que debate a especificidade deste subgénero vinculado à crença cristã católica e ao poder da fé na cura. No entanto, as informações fornecidas na «Introdução» ao género (bem como nas notas dos informantes apensas aos textos) são mais de ordem etnográfica, ao invés do que se verifica nas «Introduções» aos outros géneros, pautadas por uma erudição literária apurada.

Sobre as «Lendas», que se encontram presentes neste volume através de 24 versões, diz-nos Maria Aliete Galhoz tratar-se um «género mais ténue, nitidamente o menos funcional no domínio colectivo» (p. I7) a avaliar pela parca expressão numérica das versões recolhidas. Entendo, noutra perspectiva, que a fraca presença das lendas nesta colecção se deverá menos à funcionalidade do género (menos funcional do que um romance de assunto profano certamente não será). E as abundantes e funcionalíssimas ditas lendas urbanas? Não esqueçamos que são as próprias autoras quem afirma que as recolhas foram direccionadas maioritariamente para os três géneros: conto, romance e oração. Fica o registo, neste volume, da excelente «Introdução» de Isabel Cardigos que precede a fixação das lendas, problematizadora dos limites teóricos e classificativos do género. Destaco, por fim, a profícua bibliografia sobre os géneros que aqui são publicados pela primeira vez bem como a actualização bibliográfica referente à adenda.

Como nota derradeira, e pese embora os reparos que, afinal, acabam por não deixar mácula numa obra de tamanha envergadura, não será despropositado afirmar que, com os cinco volumes de Património Oral do Concelho de Loulé, Maria Aliete Galhoz, Idália Farinho Custódio e Isabel Cardigos colocaram o Concelho 
Reviews

de Loulé numa posição inédita, em Portugal. Atrever-me-ia a afirmar que nenhum outro concelho, neste país, se ufanará de possuir uma colecção de literatura tradicional tão completa, tão representativa e selada com um rigor científico semelhante ao que estas três especialistas depositaram neste magnânimo projecto editorial ao qual se soma a criteriosa selecção dos materiais patentes nos CD's, registos sonoros que constituem uma amostra válida da qualidade desta obra. 